\title{
An Assessment of Knowledge \& Perception among Undergraduate, Interns \& Post graduate students of the Department of Prosthodontics and Crown \& Bridge from different colleges of West Bengal Towards Disinfection of Impression, Cast \& Prosthesis: A Cross-sectional Study
}

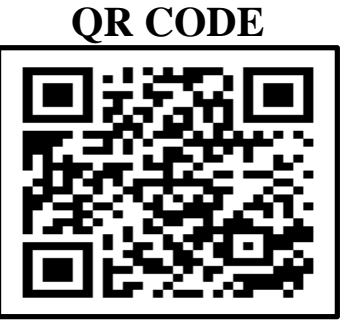

\section{SREETAMA TARAPHDAR*, ANUMITA MANNA', UTTAM KUMAR SEN², ARINDAM KARMAKAR3}

BACKGROUND: Infection control in dental practice is one of the most important factor for the treatment to be successful. Almost all of the dental procedures involve dealing with the saliva, blood and oral fluids which may have sufficient pathogens and cause cross infection through contaminated instruments, materials and surfaces. Therefore, the dental health care workers must be aware of the possible contamination and should follow the measures to prevent it.

AIM: The aim of the study is to evaluate the knowledge, awareness and practice of the undergraduate students, interns and PGTs toward infection control measures during prosthodontic treatment with their future perception.

RIALS AND METHOD: A self-assessment questionnaire-based survey was carried out among undergraduate students, interns and post graduate students of Dept. of Prosthodontics and Crown \& Bridge of various dental colleges of West Bengal to assess the knowledge and perception of infection control. Survey containing questions were randomly distributed to 250 students regarding knowledge of infection control and the methods actually followed in practice from impression making to delivery of the prosthesis in dental colleges. The questionnaire was sent to all by email to be filled electronically. Data was collected and analysed.

RESULTS: Out of 250 students 210 students (59.4\% female and $40.6 \%$ male) responded to the questionnaire. Their awareness towards disinfecting the impression, cast or prosthesis was $100 \%$ and all the participated students are aware of the fact that corona virus may spread via saliva from patients to dental health care workers. Though most of the students ( $94.3 \%)$ think it is mandatory to rinse the mouth before the impression making but they do not have proper knowledge about disinfectants i.e., glutaraldehyde, iodophor etc to be used for disinfecting the impression, cast and prosthesis. In regular practice in the clinics around $74.3 \%$ of them disinfect the cast before sending to the dental laboratory.

CONCLUSION: The knowledge about infection control during impression making is satisfactory among the students participated but there is a need to improve practice with disinfectants to minimize the cross contamination and the disease transmission and also reduce the associated morbidity for both patients and the dental practitioner. The attitude towards infection control measures is positive, but a greater practical approach is needed.

KEYWORDS: Knowledge, Attitude, Practice, Disinfection, Impression, Cast, Prosthesis

\section{INTRODUCTION}

Department of Prosthodontics of every dental colleges offers with the diagnosis, treatment planning, rehabilitation of the teeth in the oral cavity which is a good environment for the replication of multiple types of microbial agents for the transmission, inoculation and growth of a variety of agents which are both infectious and detrimental to others.

One millilitre of human saliva froma healthy individual contains about 100 million bacterial cells. With a normal salivary secretion of $750 \mathrm{ml}$ per day, about $8 \times 1010$ bacteria are shed from the oral cavity of all of the humans per day, which indicates that dental practitioners are at risk of cross infection through the contact with the saliva, blood and other oral fluids. ${ }^{1}$

In the clinics of Prosthodontics, the concern is well established that during the clinical procedures if proper infection control protocols are not maintained then clinicians and their assistants are exposed to pathogens through materials and contaminated instruments. $^{2}$

The Centres for Disease Control and prevention $(C D C), 3$ in its infection control guideline, indicated that both the impression and the cast are the potential sources of contamination and should be properly handled which prevents exposure to the clinicians, patients and the environment. ${ }^{4}$ Therefore, the use of mechanical barriers such as gloves, masks, safety glasses, aprons as well as disinfection of surfaces and instruments sterilization are basic procedures for universal precaution. Henry N. Williams, did a study in which he identified the bacterial colony types 
recovered from pumice collected from four dental laboratories indicated that the predominant bacteria recovered were nonoral microorganisms, including members of the genera Bacillus, Acinetobacter, Micrococcus, Pseudomonas, Moraxella, and Alcaligenes. On the other hand Hiroshi E Gusa et al. Reported in his study the persistent presence of microorganisms on patient-derived dental impressions and gypsum casts and highlighted the important human pathogens. ${ }^{5,6}$ Thus, dental impressions can transmit serious diseases from patient to other staff or vice versa because they are in contact with saliva and blood from patient's mouth and can transfer microorganisms to stone casts. The survival rate of the microorganisms are very long even when they are outside the oral fluids, then this is a potential health risk.

Several epidemics (such as $\mathrm{H}_{1} \mathrm{~N}_{1}, \mathrm{H}_{5} \mathrm{~N}_{1}$, avian influenza, Ebola, SARS, Zika, and Nipah) have affected India and other countries in the past, which were successfully tackled with appropriate research. The emergence of novel human coronavirus initially referred to as the Wuhan coronavirus $(\mathrm{CoV})$, currently designated as severe acute respiratory syndrome (SARS)-CoV-2, is responsible for the latest pandemic that is affecting human health and economy across the world. ${ }^{7}$

The procedures involving the use of aerosol generating high-speed handpiece which cause secretions of saliva increases the suspension of the virus into the surroundings and transmission can also occur through indirect contact by touching contaminated surfaces followed by self-delivery to the eyes, nose, or mouth[8]. In Prosthodontics clinics the clinicians are at high risk for exposure to the novel coronavirus through aerosols and possibly contaminated surfaces and indirect contact with dental laboratories and dental technicians through impressions, dental stone casts, and fixed and removable prosthetic appliances.

So, all the impressions should be sterilised or disinfected before being sent to the prosthetic laboratory or by the time they arrive there, to avoid the spread of cross infection. The disinfection of the dental impression must be done carefully. The selection of the disinfecting agent is very important, because it must have wide action spectrum without altering the physio chemical properties from the impression materials. ${ }^{9}$ Other factors, such as concentration, compatibility and also time of disinfection to each impression materials are also very important. ${ }^{10}$
Until 1991, impression rinsing under running water was the recommended practice[11] but with recent emergence of several disinfectants available reduce the count of microorganisms present on the surface of the impression by $99.99 \% .^{12}$

Current recommendations advocate the use of disinfecting solutions like formaldehyde diluted to a 2$8 \%$ solution to disinfect inanimate objects and to a $1^{-}$ $2 \%$ solution for disinfection by scrubbing, chlorine compounds, $1.12 \%$ of glutaraldehyde, $6-75 \mathrm{ppm}$ of iodophors and $1.93 \%$ of phenolic compounds. ${ }^{13}$

Awareness about the disinfection is imperative in order to protect clinicians and the patients.

\section{AIM}

The aim of the study was to determine the knowledge of undergraduates, interns and the post graduate students in the prosthodontics clinics regarding infection control and modes of infection control followed by them during impression making and fabrication of cast and the prosthesis.

\section{MATERIALS AND METHOD}

A questionnaire survey was conducted among dental students (Undergraduates, Interns and Post Graduate Students) of the Department of Prosthodontics and Crown \& Bridge from several dental colleges of West Bengal in 2021. The questionnaire was formed by the Post Graduate Student and the Faculties of the Dept of Prosthodontics and Crown \& Bridge, Haldia Institute of Dental Sciences, Haldia, Purba Medinipur, West Bengal. It was a self-administered questionnaire consisting of questions related to the assessment of the knowledge, and awareness towards infection control in prosthodontic department. The questionnaire was forwarded to students by emails to be filled, and informed consent was obtained from each student before commencing the questionnaire. Participants were given no time limit to fill the questionnaire (in days) so as to reduce induced error. Data were collected between May 2021 to September 2021.

\section{RESULTS}

The present study comprised of out of which 59.4\% were the female participant and $40.6 \%$ were male participant who responded (figure 1).

$100 \%$ of the total participants know that it is required to disinfect the impression, cast, or prosthesis as well as they are aware of the fact that corona virus may 


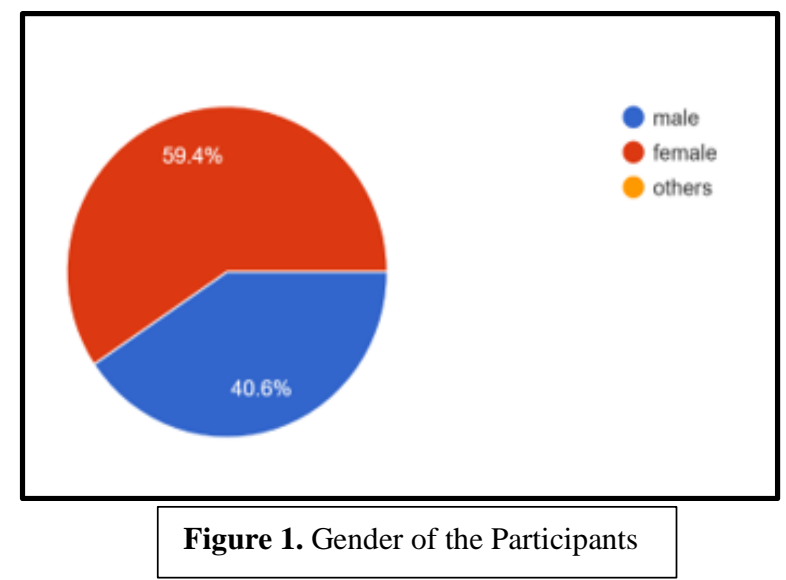

spread via patient to dental health care workers either directly or indirectly. (figure 2 and figure 3 ) but according to their response $50 \%$ of them do not follow ICMR Protocol for disinfection in COVID-19 era and only $16.7 \%$ follow the protocol whereas the rest do not know about it (figure 4). It is impressive that $94.3 \%$ of them thinks that it is necessary to rinse the patients mouth before making an impression (figure 5).

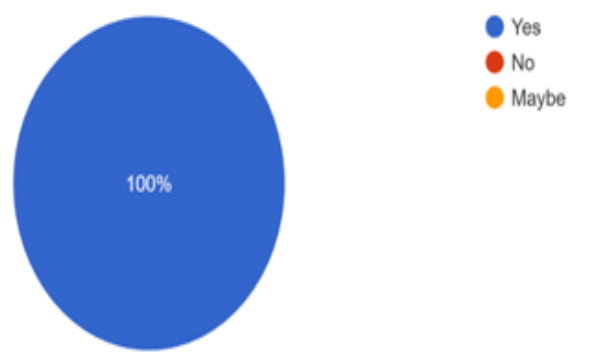

Figure 3. Response of Participants on the question "Corona Virus May Spread via Saliva From Patients to Dental Health Care Workers Either Directly or Indirectly”

Most of them are in favour of disinfecting the impression trays before making an impression but only $88.7 \%$ of them are in favour of disinfecting the adjunct instruments (figure 6) and 95.2\% wash their impression after removing from the mouth by running tap water (figure 7).
Almost all of them (93.4\%) are aware of the availability of various disinfectant and their use in particular fields are depicted in the table 1 . The table depicts that Glutaraldehyde as a disinfectant of various impression is largely accepted.

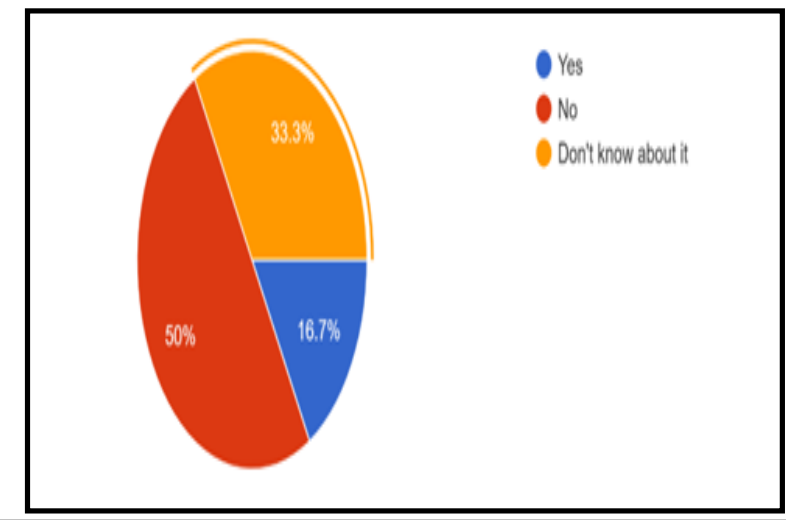

Figure 4. Response of Participants on the question "Do you follow ICMR Protocol for the disinfection in COVID 19 Era?"

The study results show that they have a misconception about alteration of minute details of the impression after disinfecting it (figure 8). This reveals that adequate knowledge regarding the chemical properties of the disinfectants and the impression material is lacking among the students.

According to this study there is a mixed response from the students as to which technique to be used as the disinfection technique for impression. $46.7 \%$ prefer immersion technique, $36.2 \%$ opted for spraying technique for the disinfection and $16.2 \%$ for washing technique (figure 9).

\section{DISCUSSION}

This cross sectional study reports the result of a survey conducted in the Dept of Prosthodontics of different colleges of West Bengal among the Undergraduate students , Interns and Post graduate students about the knowledge and perception about the disinfections of

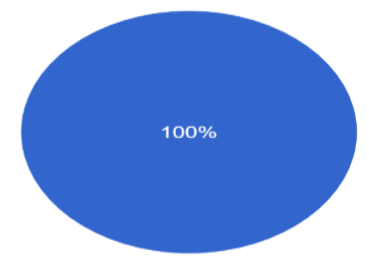

Figure 2. Response of Participants on Disinfection of the Cast, Impression or Prosthesis 


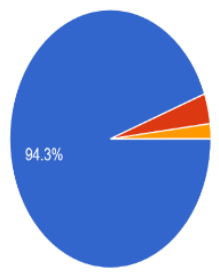

Figure 5. Response of Participants on the question "Do you Think it is Necessary to Rinse the Patient's Mouth before Making an Impression?"

impression, cast and prosthesis. In Prosthodontic Practice in different colleges while working on the patient mouth, plenty of pathogenic microorganisms can be transferred from patient to the students and from the Prosthodontic clinic to the Laboratory and vice versa if proper infection control measures are not adopted.

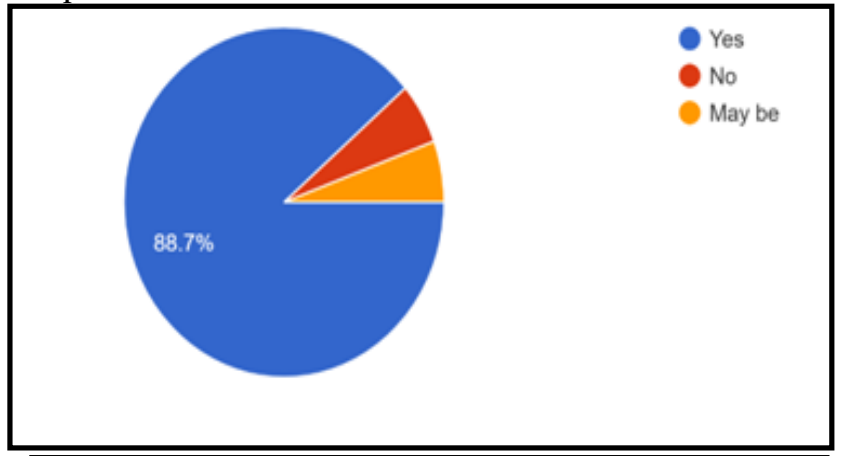

Figure 6. Response of Participants on the question "Do you Think it is Necessary to disinfect adjunct instruments (rubber bowl, mixing spatula etc)?"

Thus, the survey used in this study was to determine the knowledge and perception among the students to establish the actual methods used in disinfection of impressions prior to the pouring of the casts and also disinfection of the casts before sending it to the library. Literature suggests, that the prevalence of occupational hazard in dental health care workers is found to be

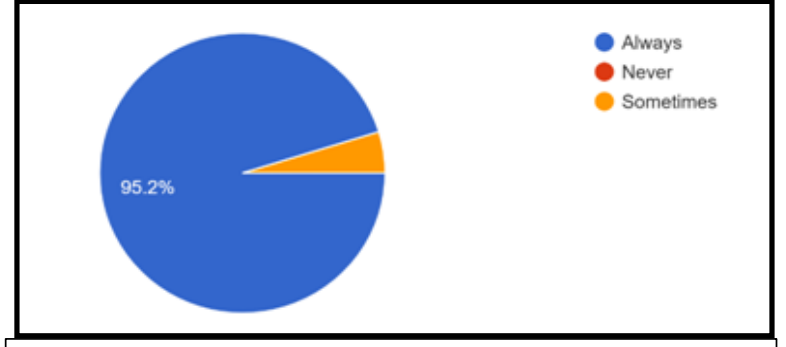

Figure 7. Response of Participants on the question "Do you Think it is Necessary to wash the impression after removing from Patient's mouth?"

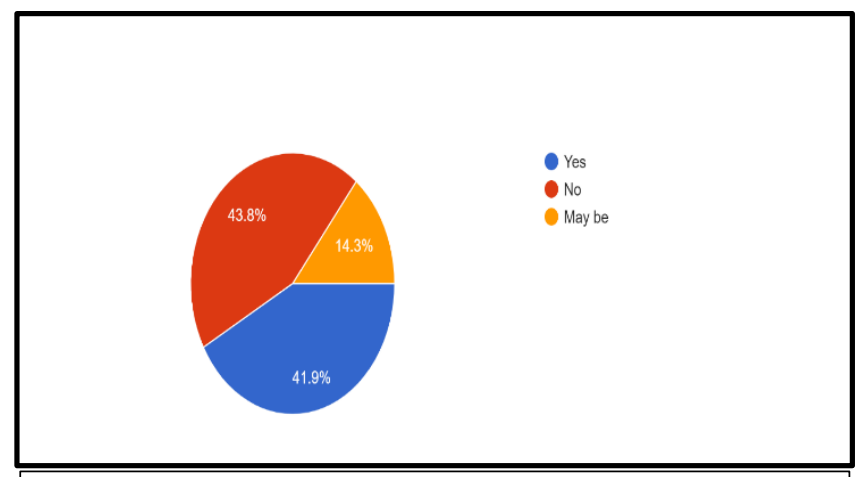

Figure 8. Response of Participants on the question "Will disinfecting the impression alter the minute details of the impression?"

$15.4 \%$ and they are 3 times at more risk of acquiring Hepatitis B infection than the general population. ${ }^{14}$

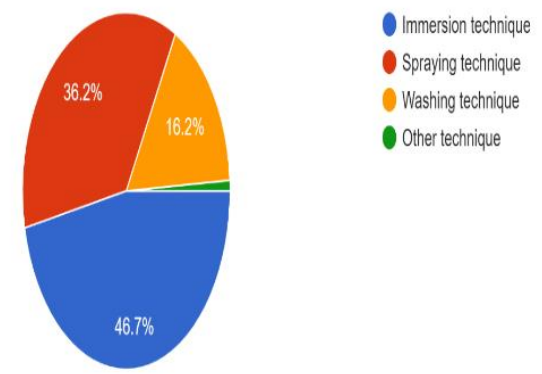

Figure 9. Response of Participants on the question "What is the Type of Disinfection Technique do you Prefer for Impression?"

Occupational exposure to blood borne pathogens can be from HIV, HBV, HCV, Mycobacterium tuberculosis, Herpes Simplex virus Type I and Type II, Staphylococci and other potentially infectious agents[15]. So, it is necessary that all the Clinicians along with students also be made aware about the infection control practice. The concept in dental infection control were developed early in the 196os (due to Hepatitis B virus infection), but this practice gained priority and was implemented only after HIV infections became epidemic and further it was prioritized in the USA after patients treated by a dentist infected by HIV were found positive for the same. ${ }^{16}$

HBV and HIV viral particle have been isolated from saliva and the latter is one of the primary screening method for HIV infection according to the Evidence Based Study. 


\begin{tabular}{|c|c|c|c|c|c|}
\hline & Alcohol & $\begin{array}{l}\text { Sodium } \\
\text { Hypochlorite }\end{array}$ & Glutaraldehyde & Iodophor & $\begin{array}{l}\text { Hydrogen } \\
\text { peroxide }\end{array}$ \\
\hline $\begin{array}{l}\text { Hydrocolloid } \\
\text { Impression }\end{array}$ & $10.6 \%$ & $33.7 \%$ & $52.5 \%$ & $3.3 \%$ & - \\
\hline $\begin{array}{l}\text { Silicone } \\
\text { Impression }\end{array}$ & $10.7 \%$ & $9 \cdot 7 \%$ & $68 \%$ & $11.7 \%$ & \\
\hline $\begin{array}{l}\text { Zinc Oxide } \\
\text { Eugenol } \\
\text { Impression }\end{array}$ & - & $23.8 \%$ & $55.4 \%$ & $17.8 \%$ & $3 \%$ \\
\hline Cast & - & $16.8 \%$ & $67 \cdot 3 \%$ & $14.9 \%$ & $1 \%$ \\
\hline Prosthesis & $15 \cdot 7 \%$ & $1.9 \%$ & $81.4 \%$ & & $1 \%$ \\
\hline
\end{tabular}

Table 1. Comparison of Various Disinfecting Agents with the Disinfection of Impression, Cast and Prosthesis

It has been proved in a study that Impression materials absorb and retain viruses and viable organisms even for 48 hours after the impression is taken and the pathogens of tuberculosis remain dangerous for several weeks[17] with alginate impression transmitting more bacteria than silicone impression. ${ }^{16}$

HBV can survive on dry blood on surfaces for upto week according to other studies. Therefore, it is imperative to use protective measures and other disinfection of all the impressions to prevent crossinfection.

The Centre for Disease Control and Prevention recommends that all patients be treated as potentially infectious $^{16}$ and the British Dental Association stated that "infection control is a core element of dental practice. $^{18}$

The Federation of Dentaire Internationale (FDI) states that all patients' prosthesis should be cleaned and disinfected before delivery to the laboratory. Similarly, the American Dental Association (ADA) recommends chemical disinfection of all impression and prosthesis. ${ }^{19,20}$

In our study $59.4 \%$ of the respondents were females and $40.6 \%$ were males (figure 1 ). This high percentage of female respondents was due to the large number of female undergraduate students, interns and postgraduate students compared to the males in the dental colleges. Also, because it was easier for the authors (being females) to access both female undergraduate and postgraduate students and interns to motivate them to respond to the questionnaire.

All the students participated in the survey (figure 2) have the knowledge that it is required to disinfect the impression, cast and the prosthesis and the students are also aware in this COVID 19 ERA that corona virus may spread via saliva to health care workers either directly or indirectly (figure 3). It was also asked whether they follow the ICMR Protocol for the disinfection in COVID 19 Era which includes the following guidelines ${ }^{21}$ for maintaining certain precautions to avoid transmission of COVID 19 during treating patients in the clinics. In the survey only $16.7 \%$ follow the proper ICMR guidelines, $50 \%$ of the respondents do not follow and the rest $33.3 \%$ do not have any idea regarding the guidelines (figure 4). From this result of the survey it is absolutely mandatory for the students who are treating the patients need to adapt guidance regarding the protocols of ICMR in order to fully protect themselves as well as the patients from the cross contamination with SARS-CoV-2.

94.3\% of the students in the study (figure 5) think that it is necessary to rinse the mouth of the patient before taking the impression to reduce the microbial load of the oral cavity and in order to reduce the cross infection. This result is quite impressive. It is revealed from the study that $88.7 \%$ of students are in favour of disinfecting the adjunct instrument that is rubber bowl, mixing spatula, facebow and its parts and various carvers and shade guide (figure 5), this awareness of disinfecting the adjunct instruments among the Students of Bengal is much more than in the study done by Alshiddi Ibrahim ${ }^{22}$ in the Prosthodontic Clinic in King Saud University in Saudi Arabia which revealed only $53.5 \%-79.1 \%$ of the students were aware.

The Centers for Disease Control and Prevention Guideline for Infection Control in Dental Health-Care Settings in 2003 provided different strategies to control infection in the dental clinic and dental laboratory. Risk of infection of laboratory technicians by saliva or blood-borne infections such as HBV has been 
documented. Therefore it is absolutely necessary to rinse the impression after taking it out from the mouth. In this study, $95.2 \%$ of the respondents rinse the impression sending it to the dental laboratory (figure 6). In the previous study by Alshidi Ibrahim ${ }^{22}$, $96.5 \%$ of the respondents rinse the impression and apply disinfectant before sending it to the dental laboratory. In Saudi Arabia Ahmad et al. ${ }^{23}$ stated that $87 \%$ of the subjects disinfect impression before it was sent to the laboratory. Other studies reported less than that, 53.7 $\%$ and $18.1 \%$. On the other hand, around $62.8 \%$ $68.65 \%$ of the study samples disinfect other dental prosthetic items (denture prosthesis, metal framework for removable or fixed prosthesis, bite registration or wax rim, and face bow and fork) before sending them to laboratory. These results suggested that additional education is required to promote routine disinfection of impressions. The study results show mixed response and indicate that they have a misconception among the students about alteration of minute details of the impression after disinfecting it in (figure 7). This result indicate that thorough knowledge regarding the chemical properties of the disinfection materials and the reaction of them with the impression material is lacking among the students. The result of this study regarding knowledge on infection control is similar to previous studies by Askarian et al. ${ }^{24}$ and Abreu et al. ${ }^{25}$ on dental students in Iran and Brazil, respectively.

There is a controversy in the disinfectant technique in between the Immersion technique $(46.7 \%)$ and Spraying technique $(36.2 \%)$ among the students according to (figure 8 ). Literature suggests both immersion and spraying have been recommended for disinfection of impressions. ${ }^{26}$ Spraying technique for disinfection showed less dimensional variability compared with immersion technique and has shown similar anti-microbial activity compared to immersion method. ${ }^{27}$ There is a variation in dimensional stability between materials which showed possibility of ZOE disinfected by immersion for 10 or 60 minutes not affecting the stability while alginate, only 10 minutes immersion not affecting the dimensional stability. ${ }^{28}$

Whereas, among the elastomers no significant variation was found on dimensional stability by immersion.

Table 1 depicts complete analysis of students knowledge on what is best disinfection material for the standard infection protocol for the various type of impression and cast and prosthesis. Majority of the students consider glutaraldehyde as the widely accepted disinfectant material for the disinfection of impression, cast and prosthesis. Sahar Al Zain. ${ }^{29}$ in his recent study in 2019 that $0.5 \%$ glutaraldehyde improved the wettability of the impression.

Immersion with gluteraldehyde showed less expansion with the impression and more expansion was seen with use of sodium hypochlorite in the other studies.

McDonnel and Russel in his study revealed that glutaraldehyde has a broad spectrum activity against any bacteria and the supreme disinfectant material among other disinfectant materials. ${ }^{30}$

So to eliminate possible contamination in the context of universal precaution, infection control programs must be recommended in the dental under graduate education and obligatory infection control courses and guidelines should be kept as a strategy to safe dental health care.

\section{CONCLUSION}

Within the limitation based on followed methodology and fact analysis, the present study show that there was lack of commitment to the standard infection control practice. Through most of them used personal protective means and knew about cross infection from oral pathogens, disinfection of impression was not followed by most of them which showed negative or core attitude towards the practice of infection control during impression making. Therefore, it is mandatory not only to ensure impression disinfection protocol. Routinely in our work place but also teach dental students and other auxiliary personnel proper technique and importance of following them. Subjects' responses showed deficiency of education to support infection control measures, and their self-assessment and satisfaction reflect their performance toward infection control policy.

\section{REFERENCES}

1. Lynge Pedersen AM, Belstrøm D. The role of natural salivary defences in maintaining a healthy oral microbiota. J Dent. 2019 Jan;80 Suppl 1:S3-S12. https://doi.org/10.1016/j.jdent.2018.o8.o10.

2. Shrestha S, Thakur SN, Dulal N. Knowledge and Practice of Infection Control in Impression Making among the Dental Health Care Professionals. Journal of College of Medical Sciences-Nepal. 2019;15(4):244-8. https://doi.org/10.3126/jcmsn.v15i4.24673

3. Centers for Disease Control and Prevention. 2003 CDC infection control recommendations for dental 
health-care settings. Compendium of continuing education in dentistry (Jamesburg, NJ: 1995). 2004 Jan;25(1 Suppl):43-53.

4. Bhat VS, Shetty MS, Shenoy KK. Infection control in the prosthodontic laboratory. The Journal of Indian Prosthodontic Society. 2007 Apr 1;7(2):62.

5. Pavez M, Troncoso C, Osses I, Salazar R, Illesca V, Reydet P, Rodríguez C, Chahin C, Concha C, Barrientos L. High prevalence of CTX-M-1 group in ESBLproducing enterobacteriaceae infection in intensive care units in southern Chile. Brazilian Journal of Infectious Diseases. 2019 Jul 18;23:102-10.

6. .Sinha DK, Kumar C, Gupta A, Nayak L, Subhash S, Kumari R. Knowledge and practices about sterilization and disinfection. Journal of family medicine and primary care. $2020 \mathrm{Feb} ; 9(2): 793$.

7. Prasad S, Potdar V, Cherian S, Abraham P, Basu A, ICMR COVID Team. Transmission electron microscopy imaging of SARS-CoV-2. The Indian journal of medical research. 2020 Feb;151(2-3):241.

8. Centers for Disease Control and Prevention. Interim infection prevention and control recommendations for patients with suspected or confirmed coronavirus disease 2019 (COVID-19) in healthcare settings.

9. Fisher WT, Chandler HT, Brudvik JS. Reducing laboratory contamination. The Journal of prosthetic dentistry. 1972 Feb 1;27(2):221-5.

10. Abdullah MA. Surface detail, compressive strength, and dimensional accuracy of gypsum casts after repeated immersion in hypochlorite solution. The Journal of prosthetic dentistry. 2006 Jun 1;95(6):462-8. 11. Kugel G, PERRY RD, FERRARI M, LALICATA P. Disinfection and communication practices: a survey: of US dental laboratories. The Journal of the American Dental Association. 200o Jun 1;131(6):786-92.

12. Correia-Sousa J, Tabaio AM, Silva A, Pereira T, Sampaio-Maia B, Vasconcelos M. The effect of water and sodium hypochlorite disinfection on alginate impressions. Revista Portuguesa de Estomatologia, Medicina Dentária e Cirurgia Maxilofacial. 2013 Jan 1;54(1):8-12.

13. Lang BR, Lepe X, Johnson GH, Berg JC. Surface characteristics of polyether and addition silicone impression materials after long-term disinfection. The Journal of prosthetic dentistry. 1995 Aug 1;74(2):181-6.

14. Hilton TJ, Schwartz RS, Bradley DV, Hilton TJ, Schwartz RS, Bradley Jr DV. Immersion disinfection of irreversible hydrocolloid impressions. Part 2: Effects on gypsum casts. International Journal of Prosthodontics. 1994 Sep 1;7(5).

15. Choël L, Grosgogeat B, Bourgeois D, Descotes J. Occupational toxic risks in dental laboratory technicians. Journal of Environmental Medicine. 1999;1(4):307-14.

16. Marya CM, Shukla P, Dahiya V, Jnaneswar A. Current status of disinfection of dental impressions in Indian dental colleges: a cause of concern. The Journal of Infection in Developing Countries. 2011 Nov 9;5(11):776-80.

17. de Souza RA, Namen FM, Jr JG, Vieira C, Sedano HO. Infection control measures among senior dental students in Rio de Janeiro State, Brazil. Journal of public health dentistry. 2006 Sep;66(4):282-4.

18. Shrestha A. Viral hepatitis in Nepal: past, present, and future. Euroasian journal of hepatogastroenterology. 2016 Jan;6(1):59.

19. British Dental Association. The control of crossinfection in dentistry. London: British Dental Association; 1991.

20. El-Kholy SM, Sedky NA. Application of infection control procedures in dental laboratories in alexandria governorate and the efficacy of various disinfectants on the mostly used impression materials. Dental Journal 2012;58(2377):2387.

21. Amato A, Caggiano M, Amato M, Moccia G, Capunzo M, De Caro F. Infection control in dental practice during the COVID-19 pandemic. International journal of environmental research and public health. 2020 Jan;17(13):4769.

22. Alshiddi IF. Attitude and awareness of dental students and interns toward infection control measures in prosthodontic clinics. Journal of International Oral Health. 2015 Dec 1;7(12):10.

23. Ahmad IA, Rehan EA, Pani SC. Compliance of Saudi dental students with infection control guidelines. International dental journal. 2013 Aug 1;63(4):196-201. 24. Askarian M, Asadian O. Infection control practices among dental professionals in Shiraz Dentistry School, Iran.

25. Abreu MH, Lopes-Terra MC, Braz LF, Rímulo AL, Paiva SM, Pordeus IA. Attitudes and behavior of dental students concerning infection control rules: a study with aı-year interval. Brazilian dental journal. 2009;20(3):221-5.

26. Infection control recommendations for the dental office and the dental laboratory, Infection control recommendations for the dental office and the dental laboratory. ADA Council on Scientific Affairs and ADA Council on Dental Practice. J Am Dent Assoc. 1996 May;127:672-8o.

27. Johnson GH, Chellis KD, Gordon GE, Lepe X. Dimensional stability and detail reproduction of irreversible hydrocolloid and elastomeric impressions disinfected by immersion. The Journal of prosthetic dentistry. 1998 Apr 1;79(4):446-53. 
28. Saber FS, Abolfazli N, Kohsoltani M. The effect of disinfection by spray atomization on dimensional accuracy of condensation silicone impressions. Journal of dental research, dental clinics, dental prospects. 2010;4(4):124.

29. AlZain S. Effect of chemical, microwave irradiation, steam autoclave, ultraviolet light radiation, ozone and electrolyzed oxidizing water disinfection on properties of impression materials: A systematic review and metaanalysis study. The Saudi dental journal. 2020 May 1;32(4):161-70.

30. McDonnell GE. Antisepsis, disinfection, and sterilization: types, action, and resistance. John Wiley \& Sons; $2020 \mathrm{Jul} 10$.

Cite this article as:

Taraphdar S, Manna A, Sen UK, Karmakar A. An Assessment of Knowledge \& Perception among Undergraduate, Interns \& Post graduate students of the Department of Prosthodontics and Crown \& Bridge from different colleges of West Bengal Towards Disinfection of Impression, Cast \& Prosthesis- A Crosssectional Study. Int Healthc Res J. 2022;5(11):OR1-OR8. https://doi.org/10.26440/IHRJ/0511.02497

\section{AUTHOR AFFILIATIONS: (*Corresponding Author)}

1. Postgraduate Trainee-Department of Prosthodontics, Haldia Institute of Dental Sciences \& Research, West Bengal, India.

2. Professor \& Principal -Department of Prosthodontics, Haldia Institute of Dental Sciences \& Research, West Bengal, India.

3. Professor - Department of Prosthodontics, Haldia Institute of Dental Sciences \& Research, West Bengal, India. 